\title{
El poema dramático cortazariano Los Reyes: el hipertexto lírico como superación del mito trágico
}

\author{
Cynthia GABBAY \\ Universidad Hebrea de Jerusalén
}

\begin{abstract}
RESUMEN
Dentro del marco de análisis intertextual, la primera obra de Julio Cortázar se caracteriza por sus relaciones dialógicas con diferentes niveles textuales y extratextuales: el genérico, el poético, el filosófico y el histórico-cultural. Los Reyes no es una excepción, y sobre él se centra este artículo en el que se ofrece la identificación y el análisis del topos reminiscente del Minotauro y el laberinto en dicho poema dramático.
\end{abstract}

Palabras clave: Julio Cortázar, Los Reyes, poesía, intertextualidad, Minotauro, laberinto.

The dramatic poem cortazariano Los Reyes: the lyric hypertext like overcoming of the tragic myth

\begin{abstract}
Inside the frame of intertextual analysis, the Julio Cortázar's first work is characterized by his relations dialógicas by different textual levels and extratextuales: the generic one, the poetical one, the philosophical one and the historical-cultural one. Los Reyes it is not an exception, and on him it centres on this article the one that offers himself the identification and the analysis of the topos reminiscente of the Minotaur and the labyrinth in the above mentioned dramatic poem..
\end{abstract}

Key words: Julio Cortázar, Los Reyes, Poetry, Minotaur, Labyrinth.

El poema dramático Los Reyes, publicado en 1949 y compuesto dos años antes, es el tercer libro de Julio Cortázar, quien en 1938 abriera su carrera poética con el poemario Presencia y el seudónimo de Julio Denis. En 1947, Cortázar, habiendo ya firmado sus artículos, reseñas y ensayos como tal, dio a conocer su ensayo lírico Teoría del túnel, mediante el cual, además de proyectar su estratagema poético, se 
identifica con el movimiento existencialista y con el surrealismo desde una perspectiva ecléctica y sincrética.

En mi trabajo de doctorado, La lírica de Julio Cortázar: Intertextualidad y Otredad literaria (2012), ${ }^{1}$ intento echar luz sobre las relaciones intertextuales insinuadas por las primeras obras cortazarianas, así como estudiar los diversos modos por los cuales se manifiesta dicha "intertextualidad"2 o "hipertextualidad", denominada así por Gérard Genette. ${ }^{3}$ Los modos intertextuales varían, en la obra cortazariana, entre los polos extremos de la ósmosis total y la cita directa. El resultado de la estrategia intertextual es la creación de diálogos literarios y filosóficos que se entremezclan y superponen creando una extensa espiral de significaciones y una obra rica en mundos, perspectivas, pensamientos y dimensiones simultáneas.

Me propongo aquí, en el marco del análisis intertextual de la obra cortazariana, elucidar algunas de las relaciones dialógicas abiertas por el poema dramático Los Reyes. Éstas revelan implicancias que atañen diferentes niveles textuales y extratextuales: el genérico, el poético, el filosófico y el histórico-cultural. Sin embargo, me centraré esta vez en la identificación y el análisis de lo que denomino el topos reminiscente del Minotauro y el laberinto.

Al optar por el topos reminiscente de un hipotexto cardinal $^{4}$, una fábula que tiene como tema un hipotexto perteneciente a la mitología griega, Cortázar

${ }^{1}$ En la Universidad Hebrea de Jerusalén.

${ }^{2}$ El concepto moderno de "intertextualidad" tiene su origen en la perspectiva dialógica propuesta por Mijael Bajtín en 1963 (ver: Problems of Dostoievsky's Poetics. Minneapolis, University of Minnesota Press). El término "intertextualidad" es utilizado, en primer lugar, por Julia Kristeva en Semeiotike : recherches pour une semanalyse, Paris, Editions du Seuil, 1969, y, entre muchos otros, por Michael Riffaterre en Sémiotique de la poésie, Paris, Editions du Seuil, 1983, a quien, en mi trabajo, tomo como referencia central pues es quien ha desarrollado el análisis intertextual en textos líricos procediendo mediante el estudio de microestructuras textuales.

${ }^{3}$ En Palimpsestes: La littérature au second degré. Paris, Editions du Seuil, 1982.

${ }^{4}$ En mi trabajo de doctorado propongo una terminología muy precisa para el análisis intertextual. Dichos términos aparecen aquí en cursiva. He denominado hipotexto cardinal a un texto de origen, o hipotexto, al que se ha recurrido reiteradamente a lo largo de la historia cultural. El mito del Minotauro corresponde, en este sentido, a la definición de hipotexto cardinal pues su fábula ha producido numerosas versiones en los ámbitos de todas las artes, en particular, en lo que concierne a las artes dramáticas del siglo XX. Cortázar será uno de los primeros poetas y dramaturgos modernos que dieran centralidad a dicho mito. Dice al respecto Ane-Grethe Ostergaard: "La obra [Los reyes] es una reestructura del viejo mito griego del Minotauro, el que en nuestro siglo ha ejercido una atracción particular sobre varios artistas, manifestada por ej. en la revista prestigiosa de los surrealistas franceses Minotaure y en las obras de pintores como André Masson y Pablo Picasso. Con Los reyes 
establece una relación con el género griego de la tragedia, definida por Aristóteles como el relato de un mythos (relato oral):

Una tragedia [...] es la imitación de una acción elevada y también, por tener magnitud, completa en sí misma; enriquecida en el lenguaje, con adornos artísticos adecuados para las diversas partes de la obra, presentada en forma dramática, no como narración, sino con incidentes que excitan piedad y temor, mediante los cuales realizan la catarsis de tales emociones. ${ }^{5}$

Los Reyes está compuesto por una alternancia de versos endecasílabos, heptasílabos y alejandrinos que hilan la acción principal del mito griego del Minotauro. La "tragedia" cortazariana cumple todos los requisitos aristotélicos. A simple vista, esta obra simula la reescritura de una leyenda griega, y el mito del Minotauro en particular, el cual según Plutarco, ${ }^{6}$ admite diversas versiones, diversidad que no alterará su concepción trágica según los parámetros establecidos por la Poética de Aristóteles.

Cortázar, sin embargo, otorga en Los Reyes una interpretación totalmente novedosa del mito, en tanto simula la aceptación de la preceptiva aristotélica, la cual postula la acción de la fábula como el ingrediente fundamental de la tragedia. Aristóteles afirma en Poética cap. II: "Los objetos que los imitadores representan son acciones, efectuadas por agentes que son buenos o malos", 7 y en el capítulo VI, agrega: "Así la acción (lo que fue hecho) se representa en el drama por la fábula o la trama. La fábula, en nuestro presente sentido del término, es simplemente esto: la combinación de los incidentes, o sucesos acaecidos en la historia". 8

Si bien Aristóteles afirmó que el valor de una tragedia no se encuentra en la repetición mimética de la historia, sino en su reformulación en el discurso, este pensador se refería, aparentemente, al trabajo estético en sí, nunca a sus connotaciones filosóficas y/o significantes, puesto que, a su parecer, la acción

Cortázar se inscribe en esta intertextualidad, dándole al mito clásico una interpretación sugestiva en el contexto del lector contemporáneo", en "Un palacio laberinto. «Los reyes» de Julio Cortázar", en Teatro y teatristas. Estudios sobre teatro iberoamericano y argentino, (ed.) Osvaldo Pellettieri, Buenos Aires, Editorial Galerna, 1992, pp. 186-190.

${ }^{5}$ Ídem, cap. VI, p. 7.

${ }^{6}$ En Vidas paralelas, en castellano

http://www.imperivm.org/cont/textos/txt/plutarco_vidas-paralelasti-teseo.html

y en inglés Lives of Illustrious men, traducido por John Dryden y publicado por Philadelphia, David McKey Publisher, sin fecha.

\footnotetext{
${ }^{7}$ Ídem, p. 3.

${ }^{8}$ Ídem, p. 7
} 
principal era determinante respecto del efecto de la tragedia sobre el receptor. En este sentido agrega:

Lo más importante de las seis es la combinación de los incidentes de la fábula. La tragedia es en esencia una imitación no de las personas, sino de la acción y la vida, de la felicidad y la desdicha. Toda felicidad humana o desdicha asume la forma de acción; el fin para el cual vivimos es una especie de actividad, no una cualidad. El protagonista nos da cualidades, pero es en nuestras acciones -lo que hacemosdonde somos felices o lo contrario. En un drama, entonces, los personajes no actúan para representar los caracteres; incluyen los caracteres en favor de la acción. De modo que es la acción en ella, es decir, su fábula o trama la que constituye el fin o propósito de la tragedia, y el fin es en todas partes lo principal. ${ }^{9}$

Pero Los Reyes prueba que "los pensamientos de los caracteres" -el segundo componente de la tragedia según Aristóteles- rigen de modo decisivo las significancias del poema dramático. En el poema dramático cortazariano aunque la misma acción sea mantenida -es decir la exigencia de Minos de sacrificar atenienses en el laberinto, la entrada de Teseo y su confrontación con el Minotauro, así como el amor de Ariadna, aquí: "Ariana", quien busca socorrer a su amado entregándole su ovillo, el triunfo de Teseo sobre Minos, de Atenas sobre Creta-, en Los Reyes, esta acción es respetada al pie de la letra. Sin embargo, tanto la caracterización de los personajes como sus pensamientos y voluntades varían hasta aparecer incluso opuestas por completo a aquellos que componen el mito griego. Dada esta instancia, el elemento hermenéutico será fundamental en la apreciación de la fórmula trágica, pues los discursos de los personajes transforman la significación de la acción. De este modo, el lector deberá confrontar ambas versiones de la historia del Minotauro, la mítica y la cortazariana, obligado a realizar un trabajo comparativo, se verá en la necesidad de establecer una interpretación personal del poema dramático.

Además, al simular la reproducción del mito del Minotauro en el marco architextual de la tragedia, Cortázar relaciona los conceptos de mito y tragedia. Sin embargo, la eventual modificación del mito y la ruptura semántica del modus trágico provocarán una reevaluación de dicho parentesco. La tragedia, a partir del trabajo de Cortázar, no será definida ya como la "mímesis" de un mito ${ }^{10}$ (según la

${ }^{9}$ Ídem, cap. VI, p. 8.

${ }^{10}$ Aristóteles, sin embargo, admite la posibilidad de que la trama sea una fábula imaginada por el poeta en lugar de las leyendas engendradas por la tradición: "Sin embargo, aún en la tragedia hay algunos dramas sólo con uno o dos nombres conocidos en ellos; el resto es invención. $\mathrm{Y}$ existen algunos sin ningún nombre conocido, por ejemplo Anteo de Agatón, en el cual tanto los incidentes como los nombres son creaciones del poeta, y el 
exigencia de Aristóteles) sino como una interpretación de éste, por la cual, el proceso hermenéutico que tiene lugar en la dinámica texto-lector pasará a ser un componente fundamental del poema dramático.

Las diferencias con el mito griego, se encuentran en particular, en lo que concierne al Minotauro y a Ariana. Ariana ama secretamente a su hermano. Dice ella:

Sólo yo sé. ¡Espanto, aleja esas alas pertinaces! ¡Cede lugar a mi secreto amor, no calcines sus plumas con tanta horrible duda! ¡Cede lugar a mi secreto amor! ¡Ven, hermano, ven, amante al fin! ¡Surge de la profundidad que nunca osé salvar, asoma desde la hondura que mi amor ha derribado! ¡Brota asido al hilo que te lleva el insensato! ¡Desnudo y rojo, vestido de sangre, emerge y ven a mí, oh, hijo de Pasifae, ven a la hija de la reina, sedienta de tus belfos rumorosos! ${ }^{11}$

El ovillo que Ariana entrega a Teseo busca, engañosamente, salvar al Minotauro y no, como aparente, al héroe ateniense. La hija de Pasifae anhela que su hermano incestuoso comprenda el mensaje oculto:

[Narra Ariana] Los ojos de Teseo me miraron con ternura. "Cosa de mujer, tu ovillo; jamás hubiera hallado el retorno sin tu astucia." Porque todo él es camino de ida. Nada sabe de nocturna espera, del combate saladísimo entre el amor y la libertad [...]

"Si hablas con él dile que este hilo te lo ha dado Ariana". Marchó sin más preguntas, seguro de mi soberbia, pronto a satisfacerla. "Si hablas con él dile que este hilo te lo ha dado Ariana..." ¡Minotauro, cabeza de purpúreos relámpagos, ve cómo te lleva la liberación, cómo pone la llave entre las manos que lo harán pedazos! $!^{12}$

Pero el Minotauro malinterpreta a Ariana, y trágicamente, sopesando una traición de su hermana, busca con su suicidio dedicarle una venganza eterna. En tanto el elemento trágico en el mito griego no representa el núcleo de la acción, pues la historia no resulta en anagnórisis ni en peripecia -tal como lo indicara Aristóteles- , el poema Los Reyes, por su parte, sí produce una anagnórisis espeluznante respecto de la identidad de Ariana y del Minotauro enamorados.

drama no resulta por ello menos delicioso. Así pues, parece que no debemos adherirnos con firmeza a los relatos tradicionales sobre los que se basan las tragedias. Sería absurdo proceder de este modo, en efecto, aun cuando las historias conocidas lo son sólo para unos pocos, si bien ellas son un deleite para todos", idem, cap. IX, p. 11

${ }^{11}$ Buenos Aires, Alfaguara, 1996, p. 55.

12 Ídem, p. 54. 
Asimismo, el Minotauro se revela poeta, "señor de los juegos, amo del rito"13; monstruo que amenaza el orden real, con su muerte vencerá a los reyes de Atenas y Creta, al instalarse en el orden de los sueños de la especie, quedará oculto y presente y podrá así amar a Ariana en la libertad del inconsciente, aludiendo de esta forma a otros mitos universales, el del amor libre e incestuoso y el de Dionisos en éxtasis poético. El monólogo del Minotauro -que cito aquí de modo fragmentariodice:
Muerto seré más yo
[...]
Qué sabes tú de muerte, dador de la vida profunda. Mira, sólo hay un medio para matar monstruos: aceptarlos.
$[\ldots]$
¿No comprendes que te estoy pidiendo que me mates, que te estoy pidiendo la vida?
$[\ldots]$
Llegaré a Ariana antes que tú. Estaré entre ella y tu deseo. Alzado como una luna roja iré en la proa de tu nave. Te aclamarán los hombres del puerto. Yo bajaré a habitar los sueños de sus noches, de sus hijos, del tiempo inevitable de la estirpe. Desde allí cornearé tu trono, el cetro inseguro de tu raza... Desde mi libertad final y ubicua, mi laberinto diminuto y terrible en cada corazón de hombre [...]
Cuando el último hueso se haya separado de la carne, y esté mi figura vuelta olvido, naceré de verdad en mi reino incontable. Allí habitaré por siempre, como un hermano ausente y magnífico. ¡Oh residencia diáfana del aire! ¡Mar de los cantos, árbol de murmullo! ${ }^{14}$

Este poema postula la muerte como liberación, muerte que aquí adquiere doble connotación libertaria: primero, el suicidio llevará al Minotauro fuera del laberinto hacia el mundo de los sueños, el oculto deseo incestuoso de cada uno de los hombres, $\mathrm{y}$, en segundo lugar, lo conducirá hacia el perenne amor de Ariana.

El poema de Cortázar demuestra que no es la acción la que determina la tragedia, tal como lo había definido Aristóteles, cuestión que influyó sobre la poética occidental, al menos hasta el siglo de Shakespeare. Los Reyes comprueba que lo que Aristóteles denominaba "los pensamientos de los caracteres" contiene todas las implicancias de la significación trágica, $\mathrm{y}$, por otra parte, que el lenguaje es imprescindible para una reformulación hermenéutica del mito.

Además de la modificación del canon aristotélico, la nueva figura del Minotauro implica numerosas rupturas con la historia de la poética occidental, comenzando

${ }^{13}$ Ídem, p. 77.
${ }^{14}$ Ídem, pp. 67-71. Los últimos dos versos aluden al "Orfeo" de Rilke. 
con la postura platónica que propone el exilio del Poeta fuera de su república. Así como el laberinto implica el exilio del Minotauro, personaje que simboliza al poeta en el poema dramático de Cortázar, la liberación del Minotauro alude a la reivindicación de la poesía. La bipartición objetada por Nietzsche, en Nacimiento de la tragedia,${ }^{15}$ busca rescatar el lado oscuro de la cultura griega, reevaluando el lugar del dios Dionisos, figura del Eros y el caos. La sombra de Dionisos es sugerida en Los Reyes como emblema de la poesía oscura, transhumado en el personaje poeta del Minotauro. Nietzsche denuncia la apropiación de la centralidad de Dionisos, por el luminoso Apolo, quien brilla sobre la clásica Grecia con las formas definidas por el blanco mármol de la escultura; su figura inmutable es una máscara vacía, símbolo del héroe y de la individuación que se contrapone al turbulento Dionisos.

Sostengo, entonces, que la figura del Minotauro es la reencarnación intertextual de Dionisos, su voz lírica y erótica. El Minotauro, al desvanecerse, ironiza aún con la cultura que busca defenestrarlo, se burla de la Grecia clásica y sus descendientes con la frase que Platón, en su República $X$, otorga como último desprecio a los poetas. Dice Teseo en el poema cortazariano: “¡Calla! ¡Muere al menos callado! ¡Estoy harto de palabras, perras sedientas! ¡Los héroes odian las palabras!”, y responde Minotauro, con la frase platónica, que funciona aquí como nexo reminiscente al texto platónico, "Salvo las del canto de alabanza-" ${ }^{16}$ pues sólo las elegías habrían de ser legítimas en la república ideal de Platón.

En 1946, el ensayo cortazariano "La urna griega en la poesía de John Keats" aporta un elemento intratextual que viene a profundizar el procedimiento hermenéutico de Los Reyes respecto de la poética aristotélica y la visión occidental de la Grecia clásica, sumando una crítica incisiva hacia la actitud apolónica que intenta vencer el magma erótico dionisíaco imponiendo un dogma totalitario. Dice Cortázar: "De la natural vertebración del arte clásico se hizo un andamiaje, un molde donde vaciar la materia amorfa. Cierto que no todo es culpa del pensar moderno; Aristóteles y luego Horacio lo preceden en esta reducción a la técnica". ${ }^{17}$ Según Cortázar fue el romanticismo el responsable de restablecer la dualidad helénica, "quien reaccionando contra la subordinación de valores estéticos a garantías instrumentales, aprehenderá el genio helénico en su total presentación estética". ${ }^{18}$

La poética cortazariana, se inicia tempranamente, por lo tanto, con la sublevación ante el canon literario y el dogma estético. Su obra futura será un magma dionisíaco en busca de lo indecidible y el interregno, espacios donde el

\footnotetext{
${ }^{15}$ Buenos Aires, Alianza Editorial, 2007.

${ }^{16}$ Ibídem, p. 72.

${ }^{17}$ En Obra Crítica 2, Buenos Aires, Suma de Letras Argentina, p. 37.

${ }^{18}$ Ídem, p. 39.
} 
decir pueda ser un silencio. Si bien, el ensayo citado adjudica al romanticismo la ruptura con el canon occidental, la experiencia cortazariana se materializó con el diálogo intertextual predominante en su propia época, años en que la voz existencialista buscó la desmitificación de la Grecia apolónica, precisamente, mediante la apropiación del mito clásico. Ejemplos de este trabajo fueron la obra de Albert Camus, El Mito de Sísifo de 1942 y la obra de Sartre, Las moscas, ${ }^{19}$ de 1943.

Asimismo, el francés André Gide publicó en 1946 su monólogo dramático Teseo. El texto de Gide juega un rol importante en el diálogo intertextual que se construyó durante el siglo XX en torno al topos reminiscente del Minotauro y el laberinto, y manifiesta un funcionamiento similar al de Los Reyes, centrado en la reformulación hermenéutica respecto del hipotexto cardinal. Así como lo ha hecho Los Reyes, Thésée aprovecha los intersticios líricos -o elipsis hipotextuales- del hipotexto cardinal para producir momentos de novedosas anagnórisis. De modo general, el texto de Gide -así como el de Cortázar- modifica la significación del mito mediante agregados de orden psicológico, el cual, en el análisis de Los Reyes he descripto en términos aristotélicos como una intensificación o mayor focalización en el "pensamiento de los caracteres". Finalmente, al igual que Los Reyes, Thésée presenta el laberinto, a través de los testimonios de Dédalo e Ícaro, como el reino poético gobernado por la presencia del espíritu dionisíaco.

Por su parte, el relato "La casa de Asterión" de Jorge Luis Borges, publicado el mismo año de 1949 parece completar el poema dramático de Cortázar en lo que denomino un fenómeno de intertextualidad simbiótica. "La casa de Asterión" se desarrolla como monólogo interior del Minotauro, ser que se identifica con el filósofo, Platón tal vez, al afirmar: "como el filósofo, pienso que nada es comunicable por el arte de la escritura", a diferencia del Minotauro cortazariano que enarbola su voz de poeta. El relato de Borges se cierra con el cambio de perspectiva en la voz de Teseo: "-iLo creerás, Ariadna? -dijo Teseo-. El minotauro apenas se defendió". ${ }^{20}$ Dicha declaración adquiere significación en el relato con la precedente afirmación de Asterión, asegurando esperar a su redentor: "¿Cómo será mi redentor?, me pregunto. ¿Será un toro o un hombre? ¿Será tal vez un toro con cara de hombre? ¿O será como yo?"21 Si bien, el relato de Asterión y el poema del Minotauro parecen completarse uno en el otro, el poema de Cortázar busca mantener la apariencia trágica bajo la preceptiva aristotélica. El relato de Borges, por su parte, no ubica el elemento anagnórico en el nivel de los personajes, sino que apela a la capacidad interpretativa del lector para identificar a Asterión con el

${ }^{19}$ La obra de Sartre trae el mito de Orestes y Electra dando muerte a Clitemnestra y Egisto en venganza por haber asesinado al rey Agamenón.

${ }^{20}$ En El Aleph, Madrid, Alianza Editorial, p. 72.

${ }^{21}$ Ídem, p. 72. 
Minotauro a raíz de la entrada de Teseo. Dicha estrategia ubica el elemento de la anagnórisis en el nivel de la lectura. De este modo, Borges hace de la anagnórisis una herramienta estética y efectiva, en tanto que el poema dramático de Cortázar lo retoma como clave trágica.

En el nivel del estudio intertextual, por lo tanto, la problemática del género literario tiene repercusiones en el nivel poético y filosófico, alcanzando también dilemas éticos que, sin duda, infieren sobre las narrativas y poéticas de la realidad contemporánea. En este sentido menciona Cortázar, en "La urna griega de John Keats" la existencia de una similitud política entre la mitología griega y la época romántica, ${ }^{22}$ similitud alterna, probablemente, a la que llevó a los escritores de los años '40 a resignificar el gran aparato de la mitología occidental, tal como lo exigía en 1790 el manifiesto del primer romanticismo alemán bajo el nombre de "El más antiguo programa sistemático del idealismo alemán" (Hegel, G, Hölderlin, F., Schelling). ${ }^{23}$

En mi estudio de la intertextualidad de la lírica cortazariana adjudico la intertextualidad genérica a una subcategoría de lo que denomino topos reminiscente, el cual se refiere a fenómenos intertextuales centrados en lo genérico, lo simbólico o lo temático. En el caso de Los Reyes, es claro, dicho topos reminiscente hace referencia tanto al género de la tragedia como a una serie de símbolos: el hilo de Ariadna, el laberinto y el Minotauro. El poema dramático cortazariano reformula mediante una nueva hermenéutica cada uno de esos elementos.

El Minotauro cortazariano se revela como un personaje netamente existencialista en cuanto opta por la libertad en un acto de voluntad que vence el temor a la muerte, dando lugar a una reescritura de la clave cultural a través de una renovada hermenéutica del mito. La obra de Cortázar presenta la opción del suicidio como voluntad que conduce a la significación del espíritu -opción que Albert Camus había objetado en su obra el Mito de Sísifo, y sin embargo la postulaba como la pregunta filosófica a la que todo filósofo debiera responder. El Minotauro busca dar significancia a su existencia mediante un lenguaje antidiscursivo, la palabra de la muerte, aquella que sabe superar el mito, es decir, quiere acabar con el discurso como fórmula, renegando del hilo tendido que aparenta una salvación, hilo que es la metáfora de la narración preestablecida. Es sólo con la aceptación de su voz lírica, que el Minotauro podrá dar el paso a lo inenarrable, y, así, tener acceso al amor eterno en el alma de todos los seres de la especie. Por otra parte, la figura del

\footnotetext{
${ }^{22}$ Ver op. cit., p. 46.

${ }^{23}$ Ver Revista Hieronymus Complutensis, Número 1, Instituto Universitario de Lenguas Modernas y

Traductores, 1995, traducción de Miguel Ángel Vega, pp. 117-119, en

http://es.scribd.com/doc/40032412/Programa-del-idealismo-aleman
} 
Minotauro, es emblema que mezcla lo lírico y lo fantástico, elemento que a mi parecer, implicó la subjetivación más auténtica del existencialismo cortazariano, materializado fundamentalmente en su cuentística neofantástica.

Esta formulación poética, reúne tres elementos: la muerte, la poesía y el Eros. Éste último desborda en el lenguaje de Ariana y del Minotauro, en extrema disonancia con el lenguaje racionalista de Teseo y Minos. La procreación del hombre toro es relatada desde la mirada de Atxo como acto erótico que tiene el poder de explosionar el orden lógico del lenguaje racional:

El toro vino a ella como una llama que prende en los trigos.

Todo el oro fúlgido se oscureció de pronto y Atxo, desde lejos, oyó el alto alarido de Pasifae. Desgarrada, dichosa, gritaba

Nombres y cosas, insensatas nomenclaturas y jerarquías ${ }^{24}$

La génesis del Minotauro por lo tanto promueve su identificación con lo lírico, el erotismo del lenguaje, busca romper con el dogma mitológico y el orden cultural establecido. Los tres elementos mencionados, la muerte, el lirismo y la erótica, son recursos característicos de la simbología que acompaña al dios Dionisos, el cual, según el mito, rescata a Ariadna de la isla desierta en la cual la había abandonado Teseo después de haber vencido al Minotauro. Esto permite afirmar, que el poema dramático de Cortázar, al postular una ruptura con la linealidad de la leyenda, promueve una lectura que logra explicar subrepticiamente elementos del discurso que no tenían explicación racional en la linealidad de la narración tradicional. Esta elección poética, implica asimismo una relación intertextual con el texto mencionado de Nietzsche, el cual alude a la necesidad de recobrar y reinsertar el legado dionisiaco en la cultura.

Finalmente, en el estudio de la intertextualidad, es posible postular la hipótesis de la aparición de utotextos o intertextos utópicos, intertextos a futuro, posibilitados a priori por la situación enigmática a la que abre cada texto literario. En este caso, existe un texto de Michel Foucault que puede imaginarse como utotexto del poema Los Reyes, con el nombre de "Ariadna se ha colgado". ${ }^{25}$ En dicho ensayo, Foucault, imagina el suicidio de Ariadna, consumida por la espera de Teseo. Foucault imagina a Teseo, yendo al encuentro del Minotauro, no para acabar con el monstruo,

${ }^{24}$ El mismo relato de Atxo se verá desmembrado cuando en su clímax el narrador muera "en mitad de una palabra", ibidem, p. 20.

${ }^{25}$ En "Ariane s'est pendue", Dits et écrits 1954-1988, Paris, Gallimard, 1994, pp. $767-$ 771, texto fechado en 1969. 
sino para fundirse en la infinita diversidad de su ser, ${ }^{26}$ identificándolo -al igual que, tácitamente, lo hace Los Reyes-, con el dios "Dionisos enmascarado, Dionisos disfrazado, repetido hasta el infinito". ${ }^{27}$ El ensayo dramático de Foucault, como utotexto de Los Reyes, continúa, entonces, sus mismos cuestionamientos, profundizándolos, estableciendo un diálogo con sus postulados, repitiéndolo en la misma espiral que rompe con las repeticiones para ir siempre un poco más allá de lo dicho, distorsionado una vez más el laberinto textual en busca de más poesía. "Ariadna se ha colgado" postula asimismo el teatro como un espacio filosófico, tal como lo plantea desde la autorreferencialidad el poema dramático cortazariano.

En resumen, Los Reyes es la circunstancia de un hipertexto que explosiona el canon literario desde el cual se construye, rompiendo con los preceptos aristotélicos que sostuvieron veinte siglos de literatura. Asimismo, el poema dramático cortazariano materializa el proyecto del idealismo alemán, así como el deseo de Nietzsche, al rescatar la cara oscura de la luna griega. El nombre Dionisos no deja su huella en la obra, sin embargo, ésta busca una reivindicación de su genio. Este trabajo es realizado por el poeta desde los postulados modernos del existencialismo, instalando asimismo la pregunta filosófica en el corazón del escenario teatral. La labor intertextual conlleva paradójicamente la muerte del texto como unidad; la intertextualidad resulta en un acto poético que es muerte, que es acto erótico en el lenguaje, y conduce a la superación existencial del laberinto cultural. El diálogo poético se transfiere de hipotextos e hipertextos a utotextos, cada uno de ellos encadenándose en una espiral infinita que hace de todos los lectores, sorprendentes minotauros.

26 "Il va joyeusement vers le monstre sans identité, vers le disparate sans espèce, vers celui qui n'appartient à aucun ordre animal, qui est homme et bête, qui juxtapose en soi le temps vide, répétitif, du juge infernal et la violence génitale, instantanée, du taureau. Et il va vers lui, non pour effacer de la terre cette forme insupportable, mais pour se perdre avec elle dans son extrême distorsion", ídem, p. 767.

${ }^{27}$ La traducción es mía : "Dionysos masqué, Dionysos déguisé, indéfiniment répété" en “Ariane s'est pendue", idem, p. 768. 